\title{
Time Course of Structural Changes at Identified Sensory Neuron Synapses During Long-Term Sensitization in Aplysia
}

\author{
Craig H. Bailey and Mary Chen \\ Center for Neurobiology and Behavior, Departments of Anatomy and Cell Biology and Psychiatry, College of Physicians \\ and Surgeons, Columbia University, and New York State Psychiatric Institute, New York, New York 10032
}

\begin{abstract}
We have used the gill- and siphon-withdrawal reflex of Aplysia californica to explore the morphological basis of the synaptic plasticity that underlies long-term sensitization. In earlier studies (Bailey and Chen, 1983, 1988a), we described 2 classes of structural changes at identified sensory neuron synapses that occur following long-term sensitization: (1) increases in the number, size, and vesicle complement of active zones and (2) an overall increase in the total number of synaptic varicosities per sensory neuron. In the present study, we have begun to examine which of these anatomical changes might be necessary for the maintenance of longterm sensitization by exploring the time course over which they occur and, in particular, their duration relative to the persistence of the memory assessed behaviorally.

Toward this end we have quantitated changes in both the total number of varicosities and their active zone morphology in single HRP-labeled sensory neurons taken from long-term sensitized and control animals at different intervals (1-2 d, 1 week, and 3 weeks) following training. We have found that long-term sensitized animals examined within $48 \mathrm{hr}$ after the completion of training demonstrate an increase in the total number of varicosities per sensory neuron as well as an increase in the incidence, size, and vesicle complement of their synaptic active zones compared with control animals. The increase in the number of varicosities and active zones persists unchanged for at least 1 week, and the increase in active zone number is only partially reversed at the end of 3 weeks. By contrast, the increase in active zone size and vesicle complement is back to control levels 1 week later. The relative permanence of the changes in varicosity and active zone number and their similarity in time course to the duration of the memory strengthen the evidence that alterations in the number of sensory neuron synapses may contribute to the retention of long-term sensitization.
\end{abstract}

Central to the study of behavior and its modification is an understanding of the mechanisms by which learning is acquired and memory is retained. These mechanisms can be studied most

\footnotetext{
Received July 28, 1988; revised Oct. 10, 1988; accepted Oct. 12, 1988.

This work was supported by Grant MH37134 from the National Institute of Mental Health, Scope B of NIGHS Grant GM23540, and the McKnight Endowment Fund for Neuroscience. We thank Drs. E. R. Kandel, V. F. Castellucci, and R. D. Hawkins for critical review of the manuscript, $H$. Ayers for typing the manuscript, and L. Katz and K. Hilten for the illustrations.

Correspondence should be addressed to Dr. Craig H. Bailey, Center for Neurobiology and Behavior, Columbia University and New York State Psychiatric Institute, 722 West 168 th Street, New York, NY 10032.

Copyright (C) 1989 Society for Neuroscience $0270-6474 / 89 / 051774-07 \$ 02.00 / 0$
}

effectively in the relatively simple nervous systems of several higher invertebrates where the behavioral analysis can be carried out at the cellular and molecular level (Kandel, 1976). One such model system, the gill- and siphon-withdrawal reflex of the marine mollusc Aplysia californica, has proven particularly accessible for cellular studies of behavioral problems. This reflex can be modified by forms of both nonassociative and associative learning, each capable of giving rise to both a short- and a longterm memory (Kandel and Schwartz, 1982; Kandel et al., 1986).

One elementary form of nonassociative learning in this preparation is sensitization. The gill- and siphon-withdrawal reflex of Aplysia acquires the memory for sensitization in response to noxious stimuli such as electrical shock administered to the tail or head. The duration of this type of learning is dependent on the amount of training. A single noxious stimulus produces short-term sensitization that lasts from several minutes to more than $1 \mathrm{hr}$ (Pinsker et al., 1970). This short-term memory grades with repeated stimuli to produce long-term sensitization lasting days to several weeks (Pinsker et al., 1973; Frost et al., 1985).

Several aspects of the biochemical and biophysical mechanisms that underlie short-term sensitization are understood and involve changes in synaptic effectiveness produced by modulation of transmitter release at a common synaptic locus - the monosynaptic connections between identified mechanoreceptor sensory neurons and their follower cells (for review, see Kandel et al., 1986). Electrophysiological studies by Frost et al. (1985) have shown that the same synaptic site is involved in the storage of the long-term memory for sensitization. Recent morphological studies indicate that this enduring alteration in the strength of sensory to follower cell connections is accompanied by 2 classes of morphological change: (1) alterations in active zone morphology at identified sensory neuron synapses (Bailey and Chen, 1983) and (2) a more global trend involving modulation of the total number of presynaptic varicosities per sensory neuron (Bailey and Chen, 1988a).

The findings that functional as well as structural changes at sensory ncuron synapscs accompany long-term sensitization suggest that at least aspects of the memory can be localized to a specific synaptic locus and now permit us to analyze, in a set of neurons that are causally related to the behavior, the mechanisms underlying the acquisition and retention of a long-term memory trace. Central issues include the following: What is the time course of these changes? Which are necessary for the onset of the memory and which are required for its maintenance?

In the present study, we have sought to determine which class of structural alteration at sensory neuron synapses might be necessary for the retention of long-term sensitization by examining the time course over which they occur and, in partic- 


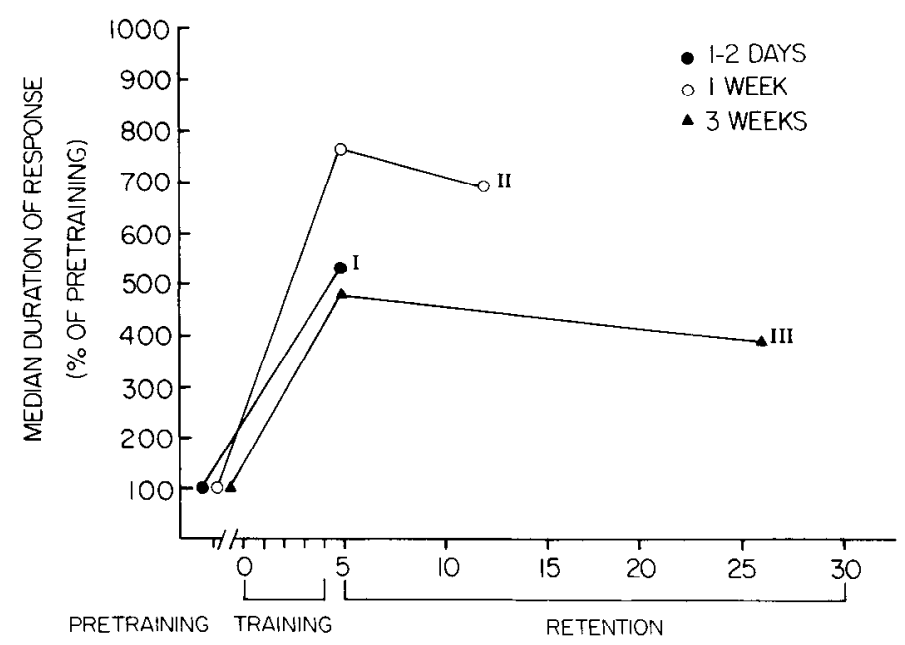

DAYS

Figure 1. Behavioral time course of long-term sensitization. Retention of sensitization was tested at different intervals following the completion of $4 \mathrm{~d}$ of long-term training. Behavioral performance of animals in each group was estimated by comparing their behavioral scores with their pretraining scores. This was achieved by summing the responses for each daily session (10 trial block, intertrial interval $30 \mathrm{sec}$ ) and expressing each as a single score compared with their own pretraining score. Animals in behavioral experiments were killed at $1-2 \mathrm{~d}(I, 529 \pm 121$ SEM, $N=6)$, 1 week $(I I, 700 \pm 173, N=4)$, and 3 weeks $(I I I, 414 \pm$ $86, N=5$ ) following training and the structure of sensory neuron synapses in each group analyzed.

ular, their duration relative to the persistence of the memory assessed behaviorally. We report here that only changes in varicosity and active zone number persist in parallel with the retention of long-term sensitization. The relative permanence of these changes and their similarity in time course to the duration of the memory suggest that alterations in the number of sensory neuron synapses are the most likely of the structural candidates to contribute to the maintenance of long-term sensitization.

\section{Materials and Methods}

Aplysia californica (70-110 gm) were used for these experiments. Animals were individually housed for a minimum of $5 \mathrm{~d}$ in circulating seawater before behavioral training. To assess their responsiveness, we delivered 2 jets of seawater to the siphon with a Water Pik. Animals were accepted for the experiment if the mean duration of their first 2 test responses (interstimulus interval, $30 \mathrm{sec}$ ) was $10 \mathrm{sec}$ or longer. The scores (total of 10 stimuli) were ranked, and the animals were randomly distributed into a control (untrained) group and a group for long-term sensitization. There were no significant differences between the groups before training. Long-term sensitization training followed the protocol of Pinsker et al. (1973) and was produced by giving animals training sessions on 4 consecutive days. Each session consisted of exposure to 4 electrical stimuli ( $100 \mathrm{~mA}$ for $2 \mathrm{sec}$ ), each separated by $1.5 \mathrm{hr}$. All electrical stimuli were delivered to the neck region through bipolar capillary electrodes. Control animals were carried under identical conditions but without training.

Experimental $(N=15)$ and control $(N=8)$ animals were tested for retention of sensitization 1-2 d, 1 week, or 3 weeks following completion of the respective training sessions. Animals were then anesthetized by intracoelomic injection of isotonic $\mathrm{MgCl}_{2}$ and the abdominal ganglion was removed from each animal and transferred to a solution of supplemented artificial seawater containing high $\mathrm{Mg}^{2+}(200 \mathrm{~mm})$ and low $\mathrm{Ca}^{2+}(1 \mathrm{mM})$ to block synaptic transmission during pinning and desheathing. After desheathing, the ganglion was bathed in seawater with a normal $\mathrm{Mg}^{2+}(55 \mathrm{mM})$ and $\mathrm{Ca}^{2+}(10 \mathrm{~mm})$ content for a minimum of $30 \mathrm{~min}$. To label presynaptic varicosities, a single sensory neuron from each animal was chosen at random, identified (Byrne et al., 1974), and intrasomatically pressure-injected with HRP (Type VI, purchased from Sigma Chemical Co., St. Louis) at a concentration of $20 \mathrm{mg} / \mathrm{ml}$ in distilled water. Following a $2 \mathrm{hr}$ incubation period to allow HRP to fill the neuropil arbor of the sensory neuron as well as its axon in the siphon nerve, ganglia were fixed, histochemically processed, and embedded in Epon (Bailey et al., 1979). Each sensory neuron was completely reconstructed by serial $20 \mu \mathrm{m}$ slab-thick sections, and the total number of HRP-labeled varicosities for each cell was counted through a blind procedure using high-resolution light microscopy (Bailey and Chen, 1988a). In all, 23 sensory neurons were analyzed in this fashion.

For the analysis of active zone morphology, 19 individual $20 \mu \mathrm{m}$ slabthick sections containing HRP-labeled varicosities were randomly chosen, re-embedded and serially thin sectioned. Complete sets of over 200 serial thin sections were taken from each re-embedded thick section. Ten thin sections (each spaced approximately 20 thin sections apart) from each re-embedded slab thick section were quantitatively analyzed. All HRP-labeled profiles on each of these thin sections were photographed and analyzed through a blind procedure. To examine in detail the fine structure of synaptic terminals of each cell we analyzed a total of approximatcly 200 thin scctions containing profiles of 693 scnsory neuron varicosities taken from 14 animals.

When an electron-dense label is present in the presynaptic neuron (as is the case for the HRP-labeled sensory neurons), the full morphology of presynaptic specializations can be masked by the blanket of reaction product. Under these circumstances, active zones can be reliably identified by the coexistence of rigidly parallel apposed membranes bounding a widened synaptic cleft that contains electron-dense material. As we have previously demonstrated (Bailey et al., 1979, 1981; Bailey and Chen, 1981, 1983, 1988b) all these features are coextensive with the presynaptic specializations and are identical to active zones found in unlabeled synapses in Aplysia. We have used them to identify active zones in the present study. Quantitation of active zone parameters was made using a Bioquant II digitizing tablet (R\&M Biometrics, Inc., Nashville, TN) interfaced with an Apple IIc microcomputcr running the Bioquant II morphometry program. The extent of active zones was determined on prints enlarged to a final magnification of $\times 60,000$ by measuring the length of the active zone segment (determined by the Bioquant II software based upon a digitized tracing) in each section. The number of vesicle profiles associated with each active zone was determined by counting the total number of vesicle profiles in each section that fell within $30 \mathrm{~nm}$ of the presynaptic active zone membrane (Bailey and Chen, 1983, 1988b).

\section{Results}

\section{Time course of the memory for long-term sensitization}

The behavioral time course of long-term sensitization following $4 \mathrm{~d}$ of training was examined by monitoring the duration of siphon withdrawal (Pinsker et al., 1973). The retention of sensitization for all animals was tested at 1-2 $\mathrm{d}$ and then either 1 or 3 weeks following the completion of training. The behavioral performance of animals in each group was estimated by comparing their behavioral scores with their pretraining scores (Fig. 1). Animals in behavioral experiments were killed 1-2 d (I), 1 week (II), and 3 weeks (III) following training, and the structure of sensory neuron synapses in each group was analyzed. By examining the nature and extent of morphological changes at sensory ncuron synapses at these different intcrvals following the completion of training, we have been able to compare directly their duration to the persistence of the memory.

\section{Time course of changes in the number of varicosities of} identified sensory neurons during long-term sensitization

Chemical synapses in the Aplysia CNS are preferentially located at small, irregularly shaped varicose expansions that occur along or at the end of fine neurites. The axonal branching pattern of individual mechanoreceptor sensory neurons has been described, and the types of varicosities that could be found along their neuropil arbor have been characterized (Bailey et al., 1979). 

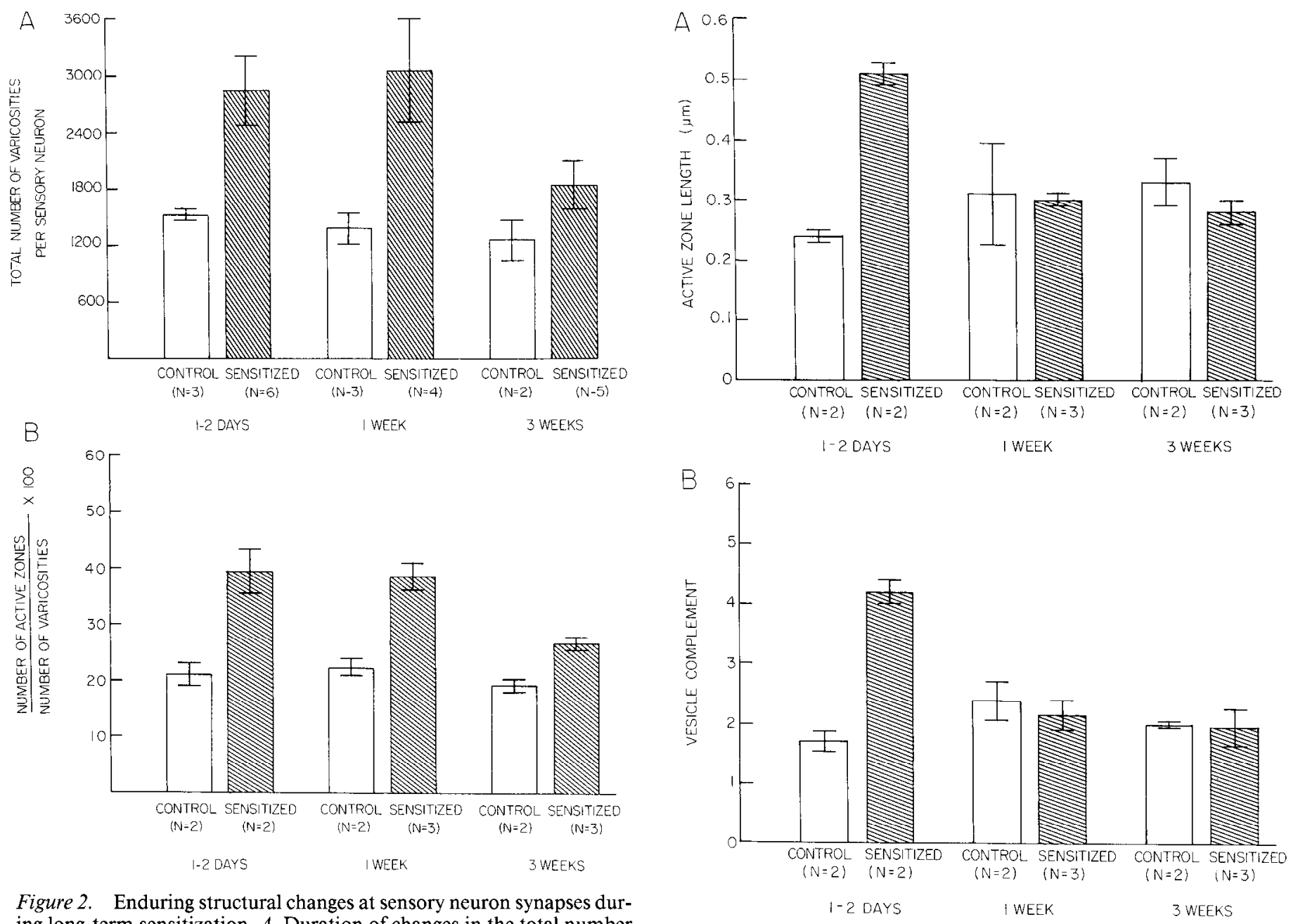

Figure 2. Enduring structural changes at sensory neuron synapses during long-term sensitization. $A$, Duration of changes in the total number of varicosities per sensory neuron. $B$, Duration of changes in the incidence of sensory neuron active zones. To determine which class of alterations in the functional architecture of identified sensory neuron synapses might underlie long-term sensitization, we compared their duration to the persistence of the memory. By examining the structure of sensory neuron synapses at different intervals following the completion of training - 1-2 d, 1 week, and 3 weeks - we have found that only the duration of changes in the number of varicosities and their active zones parallels the behavioral time course for the retention of long-term sensitization. Each bar represents the mean \pm SEM.

As reported in an earlier study (Bailey and Chen, 1988a), we have found that long-term sensitized animals examined within $48 \mathrm{hr}$ after completion of training demonstrate an increase in the total number of varicosities per sensory neuron $(2841 \pm$ 372 SEM, $N=6$ ) compared with control animals (1521 \pm 66 SEM, $N=3, t=2.4, p<0.05$ ). We now report this increase persists unchanged for at least 1 week $(3066 \pm 554$ SEM, $N=$ 4 vs $1356 \pm 154 \mathrm{SEM}, N=3, t=2.6, p<0.05)$ but is not statistically significant from controls at the end of 3 weeks $(1878$ $\pm 246 \mathrm{SEM}, N-5$ vs $1232 \pm 211 \mathrm{SEM}, N=2, t=1.51, p>$ 0.1 ; Fig. $2 A$ ).

Time course of changes in the morphology of sensory neuron active zones during long-term sensitization

Our ultrastructural analysis focused on the active zones at reembedded sensory neuron varicosities from control and longterm sensitized animals. These modified sites are thought to represent regions of the synapse where neurotransmitter is pref-

Figure 3. Transient structural changes at sensory neuron synapses during long-term sensitization. $A$, Duration of changes in active zone size. $B$, Duration of changes in the vesicle complement of active zones. Unlike the changes in varicosity and active zone number, the increases in active zone size and associated vesicles peak at 1-2 d following the completion of training and then return to control levels at 1 week and 3 weeks, making them unlikely candidates to contribute to the maintenance of long-term sensitization. Each bar represents the mean \pm SEM.

erentially released (Heuser et al., 1979; Heuser and Reese, 1981; Atwood and Lnenicka, 1986). The active zone at Aplysia synapses is similar to that described in other higher invertebrates as well as vertebrates (Palay, 1958; Gray, 1959; Pfenninger et al., 1969; King, 1976; Muller and McMahan, 1976; Wood et al., 1977; Vrensen and Nunes Cardozo, 1981) and consists of differentiated paramembranous appositions that are coextensive with focal regions of intramembranous specializations and vesicle accumulation (Bailey et al., 1979, 1981; Tremblay et al., 1979; Bailey and Chen, 1981). The active zones at HRP-labeled sensory neuron synapses were reliably identified using previously established criteria (Bailey and Chen, 1983).

We have found that long-term sensitized animals examined within $48 \mathrm{hr}$ after completion of training demonstrate an increase in the incidence $(0.395 \pm 0.03 \mathrm{SEM}, N=2$ vs $0.21 \pm$ $0.02, N=2, t=4.6, p<0.05)$, length $(0.51 \mu \mathrm{m} \pm 0.02, N=$ 2 vs $0.24 \mu \mathrm{m} \pm 0.01, N=2, t=16.3, p<0.01)$, and vesicle complement $(4.2 \pm 0.19, N=2$ vs $1.65 \pm 0.15, N=2, t=$ 


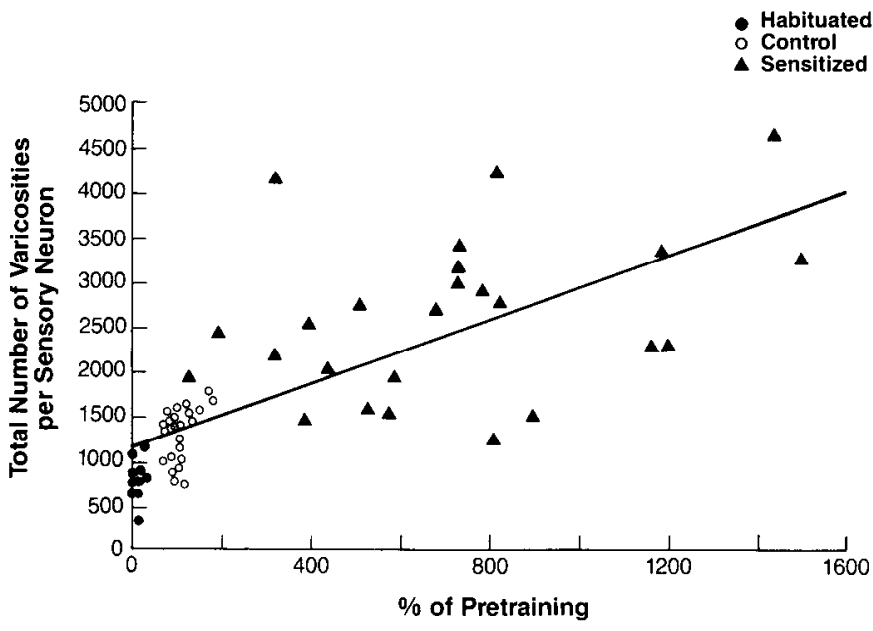

Figure 4. Correlation between changes in varicosity number and longterm memory. Wata points taken from the present and a previous study (Bailey and Chen, 1988a) and represent animals trained for long-term habituation, long-term sensitization, and untrained (control) animals. Structural changes (total number of varicosities per sensory neuron) are plotted against changes in behavioral efficacy. The responses of each 10 trial session, 24-48 hr following the completion of training, has been summed and expressed as a single median score compared to each animal's own pretraining score (Spearman's rank correlative coefficient $0.825, p<0.001)$.

$10.65, p<0.01)$ of sensory ncuron active zones compared to control animals. The nature and extent of these changes are similar to the results of a previous study (Bailey and Chen, 1983). ${ }^{1}$ The increase in active zone number is maintained at 1 week $(0.386 \pm 0.02, N=3$ vs $0.22 \pm 0.02, N=2, t=4.9, p$ $<0.05)$ and is only partially reversed at the end of 3 weeks $(0.27 \pm 0.01, N=3$ vs. $0.19 \pm 0.01, N=2, t=8.2, p<0.01$ (Fig. $2 B$, Table 1). By contrast, the increase in active zone size and vesicle complement is shorter lasting, returning back to control levels 1 and 3 weeks later (Fig. 3, Table 2).

\section{Discussion}

\section{A simple behavioral system for morphological studies of learning and memory: structural plasticity at identified synapses}

We have exploited the cellular specificity of the gill- and siphonwithdrawal reflex of $A$. californica to study how the structure of the synapse may be related to its plastic capabilities. This simple behavioral preparation undergoes 2 elementary forms of nonassociative learning, habituation and sensitization, both of which can exist in a short-term form lasting minutes to hours (Pinsker et al., 1970; Carew et al., 1971) and a long-term form that persists for several weeks (Carew et al., 1972; Pinsker et al., 1973). Aspects of the mechanisms for both types of learning are known and involve changes in efficacy at a critical site of plasticity - the presynaptic terminals of identified mechanoreceptor

\footnotetext{
I The differences in the values of active zone measurements between the present and the 1983 study are most likely due to the different methods of analysis employed in each case. Since individual sensory neuron varicosities and their active zones were completely reconstructed in the earlier study, values such as active zone size actually represent the total extent of active zone membrane. In contrast, the present study relied on a more stochastic approach, and changes in active zone morphology were based on the analysis of random thin sections Nevertheless, the percent change between naive and sensitized animals for all active zone parameters was essentially the same in both studies.
}

\begin{tabular}{|c|c|c|c|}
\hline Animal & $\begin{array}{l}\text { Vari- } \\
\text { cosities }\end{array}$ & $\begin{array}{l}\text { Active } \\
\text { zones }\end{array}$ & $\begin{array}{l}\text { Ratio of active zones } \\
\text { to varicosities (\%) }\end{array}$ \\
\hline \multicolumn{4}{|l|}{ At $1-2 d$} \\
\hline \multicolumn{4}{|c|}{ Sensitized } \\
\hline 1 & 49 & 21 & 43 \\
\hline 2 & 36 & 13 & 36 \\
\hline \multicolumn{4}{|c|}{ Control } \\
\hline 1 & 53 & 10 & 19 \\
\hline 2 & 60 & 14 & 23 \\
\hline \multicolumn{4}{|c|}{ At 1 week } \\
\hline \multicolumn{4}{|c|}{ Sensitized } \\
\hline 1 & 41 & 17 & 42 \\
\hline 2 & 50 & 17 & 34 \\
\hline 3 & 57 & 23 & 40 \\
\hline \multicolumn{4}{|c|}{ Control } \\
\hline 1 & 100 & 24 & 24 \\
\hline 2 & 34 & 7 & 21 \\
\hline \multicolumn{4}{|c|}{ At 3 weeks } \\
\hline \multicolumn{4}{|c|}{ Sensitized } \\
\hline 1 & 36 & 10 & 28 \\
\hline 2 & 41 & 11 & 27 \\
\hline 3 & 39 & 10 & 26 \\
\hline \multicolumn{4}{|c|}{ Control } \\
\hline 1 & 70 & 14 & 20 \\
\hline 2 & 27 & 5 & 19 \\
\hline
\end{tabular}

sensory neurons (Castellucci and Kandel, 1974; Klein and Kandel, 1978, 1980; Castellucci et al., 1980). Less well characterized are the morphological bases for the changes in synaptic effectiveness that underlie the short- and long-term forms of both habituation and sensitization.

To address these issues, we have combined a variety of celllabeling techniques with quantitative morphological approaches to examine structural changes at identified sensory neuron synapses that may accompany both short- and long-term memory (Bailey and Chen, 1983, 1988a, b; for review see Bailey and Chen, 1989). For both types of studies, we have identified the presynaptic varicosities of sensory neurons by the intrasomatic injection of HRP as originally described by Muller and McMahan (1976). We have increased the methodological power of the HRP technique by combining it with the analysis of serial sections. This approach has made it possible to study quantitatively complete reconstructions of unequivocally labeled identified synapses in both control and behaviorally modified animals.

We have found that the long-term memory for both habituation and sensitization is accompanied by morphological alterations on 2 levels of synaptic organization: (1) changes in focal regions of synaptic membrane specialization - the number, size, and vesicle complement of sensory neuron active zones are larger in sensitized animals than controls and smaller in habituated animals (Bailey and Chen, 1983), and (2) a parallel but more dramatic and global trend involving modulation of the total number of varicosities per sensory neuron (Bailey and Chen, 1988a). The nature and extent of these structural changes 
at sensory neuron synapses are consistent with the known behavioral efficacy of long-term habituation and sensitization (Carew et al., 1972; Pinsker et al., 1973), as well as with the results of biophysical studies that indicate an enduring alteration in the strength of the sensory to follower cell connection following long-term training (Castellucci et al., 1978; Frost et al., 1985).

There is a positive correlation between the changes in varicosity number and each behavioral modification (Fig. 4). This effect is bidirectional-sensitization increases behavioral performance as well as the total number of sensory neuron varicosities and habituation has an opposing effect decreasing both behavioral effectiveness and varicosity number. The correlation between these structural changes and the differences in the degree of behavioral efficacy exposed by 2 different experimental manipulations supports the notion that changes in the number of sensory neuron varicosities may contribute to the persistent synaptic plasticity that underlies both long-term habituation and sensitization.

\section{The time course of structural changes at sensory neuron synapses vs the behavioral time course of long-term sensitization}

In the present study we have examined which class of structural changes at sensory neuron synapses might be necessary for the maintenance of long-term sensitization by exploring the time course over which they occur and in particular their duration relative to the persistence of the memory assessed behaviorally. By examining animals at different intervals following the completion of training, we have been able to compare directly the duration of structural changes at sensory neuron synapses with the retention of the memory. This approach has allowed us to distinguish between transient and more permanent effects and thereby determine which class of structural alterations at the synapse might underlie long-term memory rather than being a stage in its development or a byproduct of its formation.

We have found that increases in the size and vesicle complement of sensory neuron active zones present $24-48 \mathrm{hr}$ following the completion of training do not persist as long as the behavioral signs of long-term sensitization. These data indicate that insofar as modulation of active zone size and associated vesicles is one of the structural mechanisms underlying long-term sensitization, it is associated with the acquisition and initial days of maintenance of the long process and not to its persistence. This phase seems to represent the initial long-term phase that appears to be a continuum of structural and functional changes at sensory neuron synapses that contributes to the progressive transition of a short-term memory trace to one of longer duration. This notion would be consistent with the results of recent biochemical studies on short- and long-term facilitation in Aplysia (D. Sweatt and F. R. Kandel, unpublished observations), morphological studies on short-term habituation in Aplysia (Bailey and Chen, 1988b), as well as studies on the induction of long-term potentiation in vertebrates (Chang and Greenough, 1984; Applegate et al., 1987). To explore this possibility directly will require a more detailed temporal analysis of the sequence of morphological events that underlies the acquisition of longterm sensitization. By studying the onset of these changes, it should be possible to distinguish how rapidly they arise and if there is any preferred order as to which class of morphological alterations is first expressed at sensory neuron synapses during the acquisition of the memory.
Table 2. Length of active zones and number of associated vesicle profiles at re-embedded sensory neuron varicosities from control and long-term sensitized animals 1-2 d, 1 week, and 3 weeks following the completion of training

\begin{tabular}{lll} 
& $\begin{array}{l}\text { Number of } \\
\text { vesicle profiles } \\
\text { Animal }\end{array}$ & $\begin{array}{l}\text { Active zone length } \\
\text { associated with } \\
\text { each active zone }\end{array}$ \\
\hline
\end{tabular}

\begin{tabular}{cccc}
\hline $\begin{array}{l}\text { At } 1-2 \mathrm{~d} \\
\text { Sensitized }\end{array}$ & & & \\
1 & $0.495 \pm 0.04^{a}$ & $4.0 \pm 0.4$ & $n=21^{b}$ \\
2 & $0.525 \pm 0.04$ & $4.4 \pm 0.5$ & $n=13$ \\
Control & & & \\
1 & $0.230 \pm 0.03$ & $1.5 \pm 0.4$ & $n=10$ \\
2 & $0.245 \pm 0.02$ & $1.8 \pm 0.4$ & $n=14$
\end{tabular}

At 1 week

Sensitized

$\begin{array}{crrr}1 & 0.304 \pm 0.03 & 2.6 \pm 0.4 & n=23 \\ 2 & 0.290 \pm 0.02 & 2 \pm 0.3 & n=17 \\ 3 & 0.315 \pm 0.02 & 1.8 \pm 0.3 & n=17 \\ \text { Control } & & & \\ 1 & 0.397 \pm 0.05 & 2.7 \pm 0.8 & n=7 \\ 2 & 0.226 \pm 0.02 & 2.1 \pm 0.3 & n=24\end{array}$

At 3 wecks

Sensitized

1

2

3

Control

1

2

$0.226 \pm 0.02$

$2.1 \pm 0.3$

$n=24$

Values equal mean \pm SEM.

" $n$, number of active zones analyzed.

Increases in the number of sensory neuron synapses parallel the time course of the memory for long-term sensitization

In contrast to the changes in active zone size and vesicle complement, we have found that the duration of changes in varicosity and active zone number are more enduring and that both persist unchanged for at least 1 week, while the incidence of active zones is only partially reversed at the end of 3 weeks. The relative permanence of these changes and their similarity in time course to the behavioral duration of the memory suggest that alterations in the number of sensory neuron synapses are the most likely of the structural candidates to contribute to the maintenance of long-term sensitization. Additional support for this idea comes from a recent study examining the effects of long-term sensitization on the structure of an identified postsynaptic target of the sensory neurons - the gill motor neuron L7. Quantitative ultrastructural analysis revealed an increase in the frequency of presynaptic contacts onto $\mathrm{L} 7$ processes in sensitized compared to control animals (Bailey and Chen, 1988c).

The increase in synapse number during long-term sensitization in Aplysia is similar to results from studies in vertebrates which indicate increases in the number of synapses following various forms of environmental manipulations, learning tasks, and electrical stimulation (Globus et al., 1973; Greenough and Volkmar, 1973; Garey and Pettigrew, 1974; Greenough et al., 1979; Lee et al., 1980; Chang and Greenough, 1984; Turner and Greenough, 1985; for reviews, see Greenough, 1984, and Green- 
ough and Chang, 1985). This growing body of morphological evidence, originating initially from studies on mammalian development and more recently embodying results from research on nonmammalian vertebrates as well as higher invertebrates, suggests that alterations in the number of synapses may contribute to memory formation and its maintenance (Greenough and Bailey, 1988). These similarities strongly suggest a role for structural plasticity during behavioral modification and provide evidence for a fundamental notion - that the timekeeping steps for a long-term memory trace may be specified by morphological change at the synapse (Bailey and Chen, 1988a). Although the specific molecular mechanisms that underlie these structural changes remain unknown-altered gene expression and protein synthesis are likely possibilities (Agranoff, 1970; Davis and Squire, 1984; Greenough et al., 1985; Goelet et al., 1986; Montarolo et al., 1986; Barzilai et al., 1989; Castellucci et al., 1989)the emerging parallels from the invertebrate and vertebrate studies suggest these mechanisms are highly conserved by evolution and may share common features throughout phylogeny.

\section{References}

Agranoff, B. W. (1970) The role of protein synthesis in memory formation in the goldfish. In Protein Metabolism of the Nervous System, A. Lajtha, ed., pp. 533-543, Plenum, New York.

$\Lambda$ pplegate, M. D., D. S. Kerr, and P. W. Landfield (1987) Redistribution of synaptic vesicles during long-term potentiation in the hippocampus. Brain Res. 401: 401-416.

Atwood, H. L., and G. A. Lnenicka (1986) Structure and function in synapses: Emerging correlations. Trends Neurosci. 9: 248-250.

Bailey, C. H., and M. Chen (1981) The active zone at $A p l y s i a$ synapses: Intramembranous organization. Soc. Neurosci. Abstr. 7: 114.

Bailey, C. H., and M. Chen (1983) Morphological basis of long-term habituation and sensitization in Aplysia. Science 220: 91-93.

Bailey, C. H., and M. Chen (1988a) Long-term memory in Aplysia modulates the total number of varicosities of single identified sensory neurons. Proc. Natl. Acad. Sci. USA 85: 2373-2377.

Bailey, C. H., and M. Chen (1988b) Morphological basis of shortterm habituation in Aplysia. J. Neurosci. 8: 2452-2459.

Bailey, C. H., and M. Chen (1988c) Long-term sensitization in Aplysia increases the number of presynaptic contacts onto the identified gill motor neuron L7. Proc. Natl. Acad. Sci. USA 85: 9356-9359.

Bailey, C. H., and M. Chen (1989) Structural plasticity at identified synapses during long-term memory in Aplysia. J. Neurobiol. (in press).

Bailey, C. H., E. B. Thompson, V. F. Castellucci, and E. R. Kandel (1979) Ultrastructure of the synapses of sensory neurons that mediate the gill-withdrawal reflex in Aplysia. J. Neurocytol. 8: 415-444.

Bailey, C. H., P. Kandel, and M. Chen (1981) The active zone at Aplysia synapses: Organization of presynaptic dense projection. $\mathbf{J}$. Neurophysiol. 46: 356-368.

Barzilai, A., T. E. Kennedy, J. D. Sweatt, and E. R. Kandel (1989) Serotonin modulates total protein synthesis and initiates a sequential alteration in the expression of specific proteins during long-term facilitation in the sensory neurons of Aplysia. Neuron (in press).

Byrne, J., V. F. Castellucci, and E. R. Kandel (1974) Receptive fields and response properties of mechanoreceptor neurons innervating siphon skin and mantle shelf in Aplysia. J. Neurophysiol. 37: 10411064.

Carew, T. J., V. F. Castellucci, and E. R. Kandel (1971) An analysis of dishabituation and sensitization of the gill-withdrawal reflex in Aplysia. Int. J. Neurosci. 2: 79-98.

Carew, T. J., H. M. Pinsker, and E. R. Kandel (1972) Long-term habituation of a defensive withdrawal reflex in Aplysia. Science 175. $451-454$.

Castellucci, V. F., and E. R. Kandel (1974) A quantal analysis of the synaptic depression underlying habituation of the gill-withdrawal reflex in Aplysia. Proc. Natl. Acad. Sci. USA 71: 5004-5008.

Castellucci, V. F., T. J. Carew, and E. R. Kandel (1978) Cellular analysis of long-term habituation of the gill-withdrawal reflex of $A p l y$ sia californica. Science 202: 1306-1308.

Castellucci, V. F., E. R. Kandel, J. H. Schwartz, F. D. Wilson, A. C.
Nairn, and P. Greengard (1980) Intracellular injection of the catalytic subunit of cyclic AMP-dependent protein kinase simulates facilitation of transmitter release underlying behavioral sensitization in Aplysia. Proc. Natl. Acad. Sci. USA 77: 7492-7496.

Castellucci, V. F., H. Blumenfeld, P. Goelet, and E. R. Kandel (1989) Inhibitor of protein synthesis blocks long-term behavioral sensilization in the isolated gill-withdrawal reflex of Aplysia. J. Neurobiol. 20: 1-9.

Chang, F.-L.F., and W. T. Greenough (1984) Transient and enduring morphological correlates of synaptic activity and efficacy change in rat hippocampal slice. Brain Res. 309: 35-46.

Davis, H. P., and L. R. Squire (1984) Protein synthesis and memory: A review. Psychol. Bull. 96: 518-559.

Frost, W. N., V. F. Castellucci, R. D. Hawkins, and F. R. Kandel (1985) Monosynaptic connections made by the sensory neurons of the gilland siphon-withdrawal reflex in Aplysia participate in the storage of long-term memory for sensitization. Proc. Natl. Acad. Sci. USA 82: 8266-8269.

Garey, L. J., and J. D. Pettigrew (1974) Ultrastructural changes in kitten visual cortex after environmental modification. Brain Res. 66 : 165-172.

Globus, A., M. R. Rosenzweig, E. L. Bennett, and M. C. Diamond (1973) Effects of differential experience on dendritic spine counts in rat cerebral cortex. J. Comp. Physiol. Psychol. 82: 175-181.

Goelet, P., V. F. Castellucci, S. Schacher, and E. R. Kandel (1986) The long and short of long-term memory-A molecular framework. Nature 322: 419-422.

Gray, E. G. (1959) Axosomatic and axodendritic synapses of the cerebral cortex: An electron microscopic study. J. Anat. 83: 420-433.

Greenough, W. T. (1984) Structural correlates of information storage in the mammalian brain: A review and hypothesis. Trends Neurosci. 7: 229-233.

Greenough, W. T., and C. H. Bailey (1988) The anatomy of a memory: Convergence of results across a diversity of tests. Trends Neurosci. 11: $142-147$.

Greenough, W. T., and F.-L.F. Chang (1985) Synaptic structural correlates of information storage in mammalian nervous systems. In Synaptic Plasticity, C. W. Cotman, ed., pp. 335-372, Guilford, New York.

Greenough, W. T., and F. R. Volkmar (1973) Pattern of dendritic branching in occipital cortex of rats reared in complex environments. Exp. Neurol. 40:491-504.

Greenough, W. T., J. M. Juraska, and F. R. Volkmar (1979) Maze training effects on dendritic branching in occipital cortex of adult rats. Behav. Neural Biol. 26: 287-297.

Greenough, W. T., H.-N. S. Hwang, and C. Gorman (1985) Evidence for active synapse formation or altered postsynaptic metabolism in visual cortex of rats reared in complex environments. Proc. Natl. Acad. Sci. USA 82: 4549-4552.

Heuser, J. E., and T. S. Reese (1981) Structural changes after transmitter release at the frog neuromuscular junction. J. Cell Biol. 88: 564-580.

Heuser, J. E., T. S. Reese, M. J. Dennis, Y. Jan, L. Jan, and L. Evans (1979) Synaptic vesicle exocytosis captured by quick freezing and correlated with quantal transmitter release. J. Cell Biol. 81: 275-300.

Kandel, E. R. (1976) Cellular Basis of Behavior: An Introduction to Behavioral Neurobiology, W. H. Freeman, San Francisco.

Kandel, E. R., and J. H. Schwartz (1982) Molecular biology of an elementary form of learning: Modulation of transmitter release by cyclic AMP. Science 218: 433-443.

Kandel, E. R., M. Klein, V. Castellucci, S. Schacher, and P. Goelet (1986) Some principles emerging from the study of short- and longterm memory. Neurosci. Res. 3: 498-520.

King, D. G. (1976) Organization of crustacean neuropil. I. Patterns of synaptic connections in lobster stomatogastric ganglion. J. Neurocytol. 5: 207-237.

Klein, M., and E. R. Kandel (1978) Presynaptic modulation of voltagedependent $\mathrm{Ca}^{++}$current: Mechanism for behavioral sensitization in Aplysia californica. Proc. Natl. Acad. Sci. USA 75: 3512-3516.

Klein, M., and E. R. Kandel (1980) Mechanism of calcium current modulation underlying presynaptic facilitation and behavioral sensitization in Aplysia. Proc. Natl. Acad. Sci. USA 77:6912-6916.

Lee, K. S., F. Schottler, M. Oliver, and G. Lynch (1980) Brief bursts of high frequency stimulation produce two types of structural change in rat hippocampus. J. Neurophysiol. 44: 247-258.

Montarolo, P. G., P. Goelet, V. F. Castellucci, J. Morgan, E. R. Kandel, 
and S. Schacher (1986) A critical period of macromolecular synthesis in long-term heterosynaptic facilitation in Aplysia. Science 234: $1249-1254$

Muller, K. J., and U. J. McMahan (1976) The shapes of sensory and motor neurons and the distribution of their synapses in ganglia of the leech: A study using intracellular injection of horseradish peroxidase. Proc. Soc. London [Biol.] 194: 481-499.

Palay, S. L. (1958) The morphology of synapses in the central nervous system. Exp. Cell Res. 5: 275-293.

Pfenninger, K., C. Sandri, K. Akert, and C. H. Eugster (1969) Contribution to the problem of structural organization of the presynaptic area. Brain Res. 12: 10-18.

Pinsker, H. M., I. Kupfermann, V. F. Castellucci, and E. R. Kandel (1970) Habituation and dishabituation of the gill-withdrawal reflex in Aplysia. Science 167: 1740-1742.
Pinsker, H. M., W. A. Hening, T. J. Carew, and E. R. Kandel (1973) Long-term sensitization of a defensive withdrawal reflex in Aplysia. Science 182: 1039-1042.

Tremblay, J. P., M. Colonnier, and H. McLennan (1979) An electron microscopic study of synaptic contacts in the abdominal ganglion of Aplysia californica. J. Comp. Neurol. 188: 367-396.

Turner, A. M., and W. T. Greenough (1985) Differential rearing effects on rat visual cortex synapses. I. Synaptic and neuronal density and synapses per neuron. Brain Res. 329: 195-203.

Vrensen, G., and J. Nunes Cardozo (1981) Changes in size and shape of synaptic connections after visual training: An ultrastructural approach of synaptic plasticity. Brain Res. 218: 79-97.

Wood, M. R., K. H. Pfenninger, and M. J. Cohen (1977) Two types of presynaptic configurations in insect central synapses: An ultrastructural analysis. Brain Res. 130: 25-45. 